\title{
Article \\ Development of a Maintenance and Spare Parts Distribution Model for Increasing Aircraft Efficiency
}

\author{
Sergio Gallego-García ${ }^{1, * \mathbb{D}}$, Javier Gejo-García ${ }^{1}$ and Manuel García-García ${ }^{2, *}$ \\ 1 Industrial Engineering Technologies of the International School of Doctorate, National Distance Education \\ University (UNED), 28040 Madrid, Spain; j_gejo@yahoo.es \\ 2 Department of Construction and Fabrication Engineering, National Distance Education University (UNED), \\ 28040 Madrid, Spain \\ * Correspondence: sgallego118@alumno.uned.es (S.G.-G.); mggarcia@ind.uned.es (M.G.-G.); \\ Tel.: +34-682-880-591 (S.G.-G.)
}

Featured Application: Spare parts distribution network design and planned maintenance intervals applied to the aviation industry.

\begin{abstract}
Maintenance management plays a key role in many industries, as maintenance determines the availability of systems, influences their lifespan, impacts customer satisfaction, and as a result affects overall investment profitability. In this context, the aviation industry seeks models to improve efficiency. Researchers seek to provide conceptual models that help to shape the industry's operations. Spare parts management plays a fundamental role in aviation, considering the predominance of planned maintenance. In this study, we analyzed the impact of the distribution network design for spare parts management and the fixed and dynamic planned maintenance intervals on the overall efficiency of an aircraft fleet. We present a conceptual model considering a variety of topics, such as distribution network design, that have been managed to a limited extent based on maintenance management. A simulation model was developed by applying the conceptual model for the aviation industry considering an aircraft fleet over its whole life cycle. The simulation model provides results concerning the impact of the distribution network, maintenance intervals, and other key factors on the efficiency of the aircraft fleet. The simulation enables a comparison of different distribution networks and maintenance strategies to decide which of them is the best fit for each spare part. The approach we propose enables companies and managers to make decisions informed by a centralized tool with all the relevant factors concerning the maintenance management of an aircraft fleet over its life cycle. As a result, managers are provided with a conceptual and simulation model for the assessment of future what-if scenarios based on aggregated databases from multiple sources without delays and with a dynamic vision of the relevant relationships between factors.
\end{abstract}

Received: 21 December 2020

Accepted: 29 January 2021

Published: 2 February 2021

Publisher's Note: MDPI stays neutral with regard to jurisdictional claims in published maps and institutional affiliations.

Keywords: maintenance management; distribution network design; spare parts management; system dynamics; aviation industry; life cycle

\section{Introduction}

Industrial maintenance is often perceived as a source of costs because it does not participate directly in the value-added process. This view, however, neglects the fact that any installation or product, regardless of its class, will fail sooner or later. Industrial maintenance therefore performs the essential service of guaranteeing production [1].

Until the 1950s, industrial maintenance played a minor role in organizations [1] and maintenance was typically carried out in an unplanned reactive way; for a long time, it has lagged behind other areas of industrial management in the application of formal techniques and/or information technology [2]. Since the 1940s the evolution of industrial maintenance can be explained in four stages. In the first stage, preventive maintenance tasks were limited to inspection, cleaning and lubrication activities [3]. The maintenance strategy was 
focused to restore machine functions as quickly as possible after a failure [4]. At this stage, breakdowns of machinery and their repairs were accepted as something necessary and not as costs with the potential to increase a company's profitability [5].

In the second stage, the complexity of the machinery grew while the number of industrial workers reduced [3], while flow production characterized by complex and linked systems was introduced [4]. As a result, the importance of downtime and the concept of preventive maintenance increased [3]. This led to the development of industrial maintenance planning and management systems [3]. Therefore, failures of individual elements had a greater impact on the entire system than previously. As a methodical approach to support the planning of maintenance measures, systematic studies on the service life of technical systems using statistics offailure intervals and duration were used [4].

In the third stage, new techniques such as TPM (total productive maintenance) and the minimization of preparation times were developed to respond to the high expectations of use of the capacity of production systems and the reduction of downtime. In the same way, maintenance tasks were related to environmental and safety systems at work [3]. The "Total Productive Maintenance (TPM) system" was established in 1969 with the transfer of routine maintenance procedures to the operators of the machines. In the 1980s, the TPM system gained recognition in the United Kingdom and United States. In Germany it was not until the 1990s that individual companies implemented productivity-oriented maintenance [1].

In the fourth stage, maintenance needs in the present day go beyond keeping up with maintenance and ensuring availability. Maintenance is used to contribute to the improvement of plants, and the ultimate objective is to avoid maintenance. The prerequisite for this is a broad concept of predictive maintenance [3]. The predictability of maintenance measures is made possible and improved through the application of new methods to maintenance problems using operations research, artificial intelligence and neural networks [4]. This has facilitated improved descriptions of operation and failure behavior of technical systems. In addition, methods and tools of information and knowledge management are available to secure knowledge and experience from the phases of the life cycle and to prepare them to be available on demand for decision-making situations [4]. Since maintenance processes and decisions affect quality, lead time, and costs and therefore the performance offered by a company in different ways, the importance of maintenance is a logical consequence of the requirements of businesses [6]. Currently, maintenance functions are used to increase the reliability of complex systems, improve the planning base, increase the proportion of preventive measures, and reduce the life cycle cost of technical systems. The influence of maintenance on investment decisions has increased over recent years. Therefore, maintenance promotes technical developments [7]. In this context, the total life cycle cost (TLC) strategy aims to make the entire cost of a facility or a product visible during its useful life and at the times in which it occurs. Most maintenance costs occur late in the life of the facility but are determined during the early stages of use [1]. In addition, maintenance costs can significantly affect an organization's profitability. In manufacturing, maintenance costs can consume $2-10 \%$ of the company's revenue and may reach up to $24 \%$ in the transport industry [8]. Most users show concern over the competitive advantage that maintenance can provide to a company. To illustrate the economic importance of maintenance, a recent study of engineering maintenance practices shows that [2]:

- United States airlines spend 9 billion dollars, approximately $11 \%$ of their operating costs, on maintenance;

- The military sector has even higher concern for the maintenance cost that accounts for about $30 \%$ of the life cycle cost of weapon system. In 1987/88 the Royal Air Force spent around 1.9 billion pounds on the maintenance of aircraft and equipment.

Consequently, maintenance departments are one of the major cost centers, costing the industry billions each year. As such, they have become a critical aspect of the profitability 
equation for many companies' [6]. An example of the life cycle cost and maintenance in the aviation industry is as follows [6]:

- The Boeing 777 Airplane has been designed for a useful life of 20 years. This involves defining what minimum scheduled and unscheduled maintenance must be performed in order to continue flying. Scheduled maintenance is performed at certain intervals based on the number of flight hours and, cycles. It consists primarily of inspections followed by maintenance, corrosion prevention, etc. Unscheduled maintenance is performed after a failure occurs. Depending on the nature of the failure, maintenance is accomplished either before the airplane is returned to revenue service or within a specified interval.

- The relationship between how often the fleet of airplanes meet scheduled take-offtime versus cost reductions are key parameters for decision-making, knowing that the delivery reliability of take-off-time is $97.8 \%$ for initial delivery and $98.8 \%$ for fleet maturity.

- Critical components of the airplane present double or triple redundancy.

- When the total cost is considered over the life cycle, it is evident that the operating and support costs of the airplane will eventually exceed the initial acquisition cost. For Boeing to make the airplane attractive to airlines, engineers must include maintenance cost savings in the design. Increased reliability means fewer failures to repair and an increased maintainability means shorter maintenance times.

In this context, design methods can lead to better maintainability, securing lower maintenance costs, better service to customers, and a lower total life cycle cost. The main practices of design to achieve good maintainability are accessibility, modularity, simplicity, standardization, fool-proofing, and inspectability [3].

Therefore, more companies and whole industries have been forced to increase their activities on research, development, and design. In the past, it was believed that every component of a complex system had an age at which a complete overhaul was needed to ensure safety and optimum operating conditions. This was the basis for scheduled maintenance programs. The limitations associated with this approach became clear when it was used to develop the preventive maintenance program for the Boeing 747 in the 1960s. The airlines knew that such a program would not be economically viable and initiated a major study to validate the failure characteristics of aircraft components. The study was concluded with the publication of the Handbook for the Maintenance Evaluation and Program Development for the Boeing 747, and based on it, the United Airlines, sponsored by the US Department of Defense, developed a comprehensive document on the relationships between maintenance, reliability, and safety called Reliability Centered Maintenance (RCM) [3]. Studies in the airline industry revealed that scheduled overhaul did not have much impact on the overall reliability of a complex item unless there was a dominant failure mode. Only $11 \%$ of the components exhibited a failure characteristic that justified a scheduled overhaul or replacement. A total of $89 \%$ showed random failure characteristics for which a scheduled overhaul or replacement was not effective. These findings redefined maintenance by focusing thinking on system function rather than operation [3].

In the literature there are concepts and mathematical formulations how to solve the distribution of spare parts for aircraft fleets such as the METRIC model that provides a method for optimize procurement, distribute existing stock and redistribute the stock of a spare parts network for a given investment level [9]. However, disposition options for specific industries in different business scenarios are yet to be explored. There is a need of developing comprehensive strategic decision models for identifying conditions under which each alternative must be selected. There are very few studies on disposition decisions, and it offers a lot of potential for future research [10]. Future maintenance management research seeks for the development of optimization models capable of incorporating information about the repair and maintenance strategy and the engineering management policies [11]. In this context, the development of simulation-based models has high potential to provide practical guidance with different maintenance strategies 
and policies [12]. In this regard, preventive maintenance and the frequency of preventive maintenance are a research focus in the field [12].

As an overview, spare parts management gaps lead to four future research areas: to develop integrated approaches to spare parts management, to define managerial guidelines, to develop maturity models as diagnosis tools, and to assess the benefits of methods by modeling the theoretical models into case study applications [13]. Furthermore, the distribution strategy for spare parts confront two main different options, allocation of spare parts in a central warehouse or in local or regional warehouses, as pointed out in a case study for spare parts logistics for the Chinese market [14]. These options refer to the strategic dilemma of defining the push, pull, or hybrid push-pull distribution strategy when designing the distribution network structure.

As a result, the goal of the paper is to develop a model with the system dynamics methodology focused on assessing what-if scenarios for strategic decision-making related to maintenance management and spare parts distribution strategy. The main differences of the pursued conceptual model with other models for aircraft spare parts management is the high level of abstraction, its focus on assessing different policies and strategies with an integrated approach and not on the exact spare parts stock distribution or optimization. Therefore, the research paper pursues to analyze the impact of the distribution network design and strategy for spare parts management. In this context, the first goal is to design a conceptual model for maintenance management and spare parts distribution management in the aviation industry to optimize any given target system of an aircraft fleet over its life cycle. The second goal is to develop a simulation model by using the system dynamics methodology to compare fixed and dynamic planned maintenance intervals and the push and pull distribution management strategies and their impact on the overall target system of an aircraft fleet over its life cycle. Moreover, the third goal is to derive managerial implications based on the conceptual model designed and, on the modeling, and results of the simulation study. In conclusion, the main hypothesis is that the proposed methodology provides guidance to managers to optimize the coordination between the strategies of the spare parts distribution network and of the maintenance activities.

\section{Materials and Methods}

\subsection{Materials}

Human mental models for complex systems usually lead us in the wrong direction because our environment usually gives us examples of systems with unexpected behaviors [9]. The reason for these experiences is that the human mind does not adapt to systems of interpretation with multiple non-linear loops such as social systems, since the understanding of them has not been necessary for man until recent historical times [15]. Therefore, only the study of the entire system as a feedback system will lead to the correct conclusions [16], since, the feedback structure of a system generates its behavior [17]. When intuition fails, computer simulations help us to deduce the behavior of a system [18]. This has led to the development of "system dynamics", developed in the 1950s as part of a research project of the MIT Sloan School of Management in collaboration with General Electric [19]. The basic components of system dynamics are closed feedback systems. It is a cybernetic methodology derived from the methods of control theory, descriptive decision theory, and various simulation techniques [20]. The system dynamics methodology uses the basis of cybernetics and systems theory, the modeling and simulation of information feedback systems, and the delays and attenuations [21].

The system dynamics methodology allows the presence of various interdependencies between many variables, both qualitatively (causal loop diagrams) and quantitatively (modeling of stocks and flows). In addition, feedback and non-linear dependencies between variables can be considered. In this way, hypotheses can be quickly established through causal relationships in dynamic systems [18]. This enablesuser-friendly modeling. Based on the system dynamics approach, complex systems and their non-linear relationships can be visualized [22] and dependencies among variables can be represented by the causal 
relationships of effect. Furthermore, decisions can be assigned to evaluations derived from cause-effect relationships in the form of feedback loops [22]. In this way, different possible actions can be evaluated through scenarios. System dynamics is a simulation technique for the study, management and solution of complex feedback problems with a focus on policy analysis and design [17]. It is an effective method that provides useful information about situations of dynamic complexityand is increasingly used to design more successful policies in business and public policy adjustments [18].

There are different software packages that can be used for system dynamics modeling such as: Anylogic, Dynamo, ithink, Powersim, Stella, and Vensim [21]. For the simulation of the case study presented here, we used the Vensim simulation software.

\subsection{Methods}

\subsubsection{Phases of the Life Cycle}

The life cycle of a technical system begins with the decision to develop or invest in a new system. Its use is intended to achieve corporate objectives, such as strengthening market positions, increasing production capacity, improving quality, and/or increasing energy efficiency and economy [4]. The life cycle of a new system is as follows:

- The decision regarding a new investment is followed by a rough planning phase of the plant with its basic parameters, followed by a detailed planning, construction, and engineering phase.

- Construction and commissioning of the production plant.

- After handing over the system to the operator, the longest life cycle phase starts.

- During the operational phase, the conditions of use, the operating regime, and maintenance interventions determine the condition of a technical system. Operating conditions influence, for example, the rate of aging and corrosion.

- At the end of the operational phase, possibilities for modernizationare technically exhausted or the ongoing maintenance costs exceed those of a new purchase and the decision is made to separate the system and dismantle it. Here, maintenance can determine the cause-effect relationship in the operating and failure behavior of the old system and document this as an experience for a new system.

Another classification for the maintenance management of a system life cycle can also be divided in four phases [23]:

- Conceptual development: Needs and risks are identified. Logistics and maintenance support are established. Mission details and lifecycle duration are evaluated.

- Validation: Large-scale development is ensured considering costs, actions, supports, and planning.

- The maintenance program, reliability determination, validation procedures, and preparation of data collection plans are prepared.

- Production: In this third phase the system is manufactured, examined, and shipped. Production is monitored, and process controls are established.

- Operation: This is the most crucial phase where it is demonstrated whether the system iscost-effective in terms of logistical support, maintenance, and operation.

\subsubsection{Maintenance and Spare Parts Management}

Industrial maintenance is defined according to DIN 31051 as the "combination of all technical and administrative measures and management measures during the life cycle of an observation unit in order to maintain the functional state or the return of the same so that it can fulfill the required function" [2]. In addition to the basic measures of maintenance, inspection, repair, and improvement, the maintenance area also includes the analysis of failure behavior, the improved detection of potential failures, and theprevention of accidents [4]. In this way, industrial maintenance encompasses the set of all measures that are necessary for the maintenance of a system [1].

Adopting a maintenance strategy is the method used to achieve the maintenance objectives. The maintenance strategy regulates when maintenance activities are carried 
out and what measures are included. When determining the maintenance strategy, legal, safety, technical, and production-relevant and economic aspects should be considered. The frequency of activities can be non-systematic or systematic. In the case of a non-systematic approach, maintenance measures are carried out when the need arises or damage occurs. With a systematic approach, measurements are taken periodically according to time or use intervals or depending on a determined or predicted status of maintenance objects [4].

With a periodic preventive maintenance strategy, the repair or replacement ofsystem components is carried out regardless of the actual condition of the component according to the defined use intervals. These can be determined based on timing (calendar time, hours of operation) or events (takeoffs and landings, distance travelled). Maintenance measures are carried out as scheduled in time windows and downtime is optimized by high repeatability and predictable processes. This contrasts with the fact that with a periodic preventative maintenance strategy, component replacement is generally carried out too soon, increasing the consumption of spare parts and materials [4]. Maintenance policies affect demand for spare parts. Preventive replacements often reduce the rate of random failures but can lead to wasted resources, so it is advantageous to coordinate maintenance activities and inventory control policies. Decision models should lead to maintenance and provisioning periods [2]. Therefore, increased use of preventive methods leads to a reduction in the cost of downtime while increasing the costs of prevention. The challenges in implementing a periodic preventive maintenance strategy are that all components of a technical system have different failure behavior and therefore expected lifespans. To optimize the utilization of component wear, regular maintenance measures should be carried out at different intervals. To this end, previous damages must be well documentedto determine replacement intervals [4].

The spare parts identification process generally starts with technical considerations. However, the efficiency of this process is affected by the quantity and quality of information available. At the equipment acquisition stage, not much information is available to the buyer. Therefore, spare parts sourcing decisions are based on spare part kits, or similar equipment failure rates and expert estimates. A complete set of service life data is assumed to be available from accelerated tests performed or from sufficiently long operation of the equipment. Based on assumptions for each component, the lifespan function, reliability function, failure rate, and mean time between failures (MTBF) can be calculated. Once the selection step is applied to all components of a technical system, the quantities required during a given period can be determined [3]. In this context, the typical decisions that are made in maintenance related to the inventory are related to the items to be stored, quantity of items, place of storage, suppliers of materials, maximum and minimum levels of supply, when to buy and pay, and price. The $\mathrm{ABC}$ analysis (an inventory categorization technique) provides a classification approach that gives information on routine and non-routine maintenance [23]:

- Item A: High priority items. They are in high demand and waiting times are minimized to acquire them.

- Item B: Items of medium priority. They are used regularly and require standardized care.

- Item C: These are low priority items. Simple but safe controls are enough to meet the demand.

\subsubsection{Distribution Network Design and Management}

Distribution logistics includes all storage and transport activities of the distribution of goods to the customer and control and inspection activities [24]. It is the link between the entrepreneurial production logistics and the customer's procurement logistics [25]. Distribution logistics is a key driver of the overall profitability of a business because it affects both the supply chain cost and customer service [26]. The goal of distribution logistics is to ensure the physical availability of products and associated flow of information [27] to achieve a high delivery service while ensuring minimal distribution costs and trying 
to acquire new customers. The delivery service goal can be subdivided into delivery time, reliability, integrity, and flexibility [28]. On the other hand, the distribution costs include storage costs, transport costs, costs of holding capital, administrative costs, and out-of-stock costs [29]. The fundamental goal of the distribution logistics is to achieve the best possiblebetween distribution performance and costs [27]. In the past, the main focus was operational and tactical problems; however, to manage logistics with success in the future, it is also required to have active strategic planning [27]. The design of a distribution network determines the potential performance and the cost structure in the long term of the logistics network and there are different frameworks that can be used to design a distribution network [27]:

- New design or re-design.

- Structure-oriented, i.e., based on the choice and quantity of locations; or resourceoriented, i.e., based on when the production, warehouse or transport capacities change.

- Static or a dynamic design.

- Cost efficiency vs. responsiveness.

- Centralized vs. decentralized.

- "Push" vs. "pull".

The processes in a supply chain are divided into two categories depending on whether they are executed in response to a customer order or in anticipation of customer orders. "Pull" processes are initiated by customer orders, whereas "push" processes are initiated and performed in anticipation of customer orders and are normally based on demand forecasts. This dilemma is important when considering strategic decisions related to supply chain design [26].

The distribution network of a company depends on the number of different storage levels, the number of warehouses at each stage, and the spatial distribution of warehouses [24]. The optimal number of storage levels within the distribution structure depends on the company and customer structure, since the means of each storage stage generates additional capital commitment and fixed costs, but in return the delivery service increases [30]. However, the goal should always be to keep the number of stages as low as possible to minimize the stocks in the factory and distribution warehouses, but without deteriorating the delivery and service levels to customers [27].

In terms of distribution logistics, various approaches can be used for the transportation of goods to customers. The advantage from one option in comparison with the others depends on the company and customer structure. The network characteristics should be decided on a case-by-case basis, and for that the typical logistics approaches for distribution networks include direct delivery, central warehouse delivery, the "milkrun" concept, transshipment points, cross-docking (one stage), and cross-docking (two stages) [31].

\section{Conceptual Model Design}

\subsection{Target System}

A set of parameters were defined within the conceptual model to define goals and measure the results of the different simulation models when facing various demand scenarios. The key performance indicators (KPIs) selected consist of a combination of distribution performance, inventory levels, maintenance intervals, spare parts demand, and economic parameters. The KPIs and their formulae are shown in Table 1. 
Table 1. Key performance indicators (KPIs) for the target system (own elaboration).

\begin{tabular}{|c|c|c|}
\hline No. & Key Indicator & Formula \\
\hline 1 & $\varnothing$ spare parts demand (units) & ( $\sum$ Spare parts demand)/Total number of weeks \\
\hline 2 & On-time delivery (OTD) (\%) & $\frac{\text { Sparte parts on time }}{\text { Total spare parts ordered }} \times 100 \%$ \\
\hline 3 & Service level (\%) & $\frac{\sum \text { Days without product backlog }}{\text { Total number of. weeks } \times \text { number of locations }} \times 100 \%$ \\
\hline 4 & $\varnothing$ spare parts backlog (units) & ( $\sum$ spare parts backlog)/Total number of weeks \\
\hline 5 & $\varnothing$ age of backlog (weeks) & [ $\sum$ backlog (units) $\times$ age of spare parts (weeks)]/Total number of weeks \\
\hline 6 & $\varnothing$ stock in network (units) & ( $\sum$ Stock central and regional warehouses)/Total number of weeks \\
\hline 7 & $\begin{array}{l}\varnothing \text { stock in Central Warehouse (CW) } \\
\text { (units) }\end{array}$ & ( $\sum$ Stock central warehouse)/Total number of weeks \\
\hline 8 & $\begin{array}{l}\varnothing \text { stock in Regional Warehouses (RW) } \\
\text { (units) }\end{array}$ & ( $\sum$ Stock regional warehouses)/Total number of weeks \\
\hline 9 & $\varnothing$ production (units) & ( $\sum$ Spare parts production)/Total number of weeks \\
\hline 10 & $\varnothing$ WIP (Work-In-Progress) (units) & ( $\sum$ Spare parts units in transportation process)/Total nnumber ofweeks \\
\hline 11 & $\varnothing$ airplane availability (\%) & $\left(1-\sum\right.$ Aircraft on ground $) \times 100 \% /$ Total number of weeks \\
\hline 12 & $\varnothing$ airplane on ground (\%) & ( $\sum$ Spare parts demand $) /$ Total number of weeks \\
\hline 14 & $\begin{array}{l}\text { Ø interval for planned maintenance } \\
\text { (operating hours) }\end{array}$ & $\begin{array}{l}\text { ( } \sum \text { Maintenance interval for planned maintenance)/Number of planned } \\
\text { maintenance intervals }\end{array}$ \\
\hline 15 & $\begin{array}{l}\varnothing \text { interval for unplanned maintenance } \\
\text { (operating hours) }\end{array}$ & $\begin{array}{l}\text { ( } \sum \text { Maintenance interval for unplanned maintenance)/Number of unplanned } \\
\text { maintenance intervals }\end{array}$ \\
\hline 16 & Inventory costs (mil. USD) & $\sum$ (Procurement + Storage + Stock-out) costs \\
\hline 17 & Production costs (mil. USD) & $\sum$ (Production cost per unit $\times$ units produced $)$ \\
\hline 18 & Transport costs (mil. USD) & $\sum$ (Transport cost per unit $\times$ units transported $)$ \\
\hline
\end{tabular}

\subsection{Model Elements}

The elements of the conceptual model refer to those physical objects that are part of a spare parts distribution network. These elements are needed to analyze, develop, and improve the existing distribution network and to design and implement a new distribution network for spare parts. Figure 1 shows the elements of the conceptual model and their characteristics.

The elements are not always available or known when defining the distribution network and maintenance management of a new maintenance system. The number and values of the elements develop over time. Moreover, the characteristics and their values have expected values that should be validated or adjusted over time withcomparisons of plan or predicted and actual or recorded data. 


\begin{tabular}{|c|c|c|}
\hline 1 & \multicolumn{2}{|c|}{ Spare part characteristics } \\
\hline & $\begin{array}{l}\text { Cost per unit (plan/actual) } \\
\text { Function and criticality (plan/actual) } \\
\text { Producer's maintenance plan (plan) } \\
\text { Applied maintenance plans (historic) } \\
\text { Lifespan and failure statistics (plan/actual) } \\
\text { Initial factor to fill the spare parts distribution netv } \\
\text { (plan/actual) }\end{array}$ & $\begin{array}{ll}\text { - } & \text { Legal requirements (plan/actual) } \\
\text { - } & \text { Maintenance tools and means (plan/actual) } \\
\text { - } & \text { Maintenance time per maintenance activity (plan/actual) } \\
\text { - } & \text { Required service level (plan/actual) } \\
\text { - } & \text { Opportunity costs as a result of stock-outs } \\
\text { k } & \end{array}$ \\
\hline 2 & \multicolumn{2}{|c|}{ Airports (Existing / planned) } \\
\hline & $\begin{array}{l}\text { Quantity of airports (plan/actual) } \\
\text { Association of airports to maintenance locations } \\
\text { (plan/actual) } \\
\text { Flight traffic volume (plan/actual) }\end{array}$ & $\begin{array}{ll}\text { - } & \text { Distance between airports and maintenance locations } \\
\text { (plan/actual) } \\
\text { - } & \text { Hangars available (plan/actual) } \\
\text { - } & \text { Maintenance staff available (plan/actual) } \\
\text { - } & \text { Maintenance tools and means available (plan/actual) }\end{array}$ \\
\hline 3 & \multicolumn{2}{|c|}{ Maintenance locations } \\
\hline & $\begin{array}{l}\text { Quantity of maintenance locations (plan/actual) } \\
\text { Association of airports to maintenance locations } \\
\text { (plan/actual) } \\
\text { Warehouse capacity at maintenance locations } \\
\text { (plan/actual) }\end{array}$ & $\begin{array}{ll}\text { - } & \text { Distance between airports and maintenance locations } \\
\text { (plan/actual) } \\
\text { - } & \text { Hangars available (plan/actual) } \\
\text { - } & \text { Maintenance staff available (plan/actual) } \\
\text { - } & \text { Maintenance tools and means available (plan/actual) }\end{array}$ \\
\hline
\end{tabular}

Figure 1. Elements and their characteristics (own elaboration).

\subsection{Model Development and Methodology}

The definition of the model starts by listing the considered distribution and maintenance management and planning tasks considered in the development of the conceptual model. They can be observed in Figure 2:

\section{Maintenance Management}

\section{$\underset{1}{\rightleftarrows}$ Distribution Management}

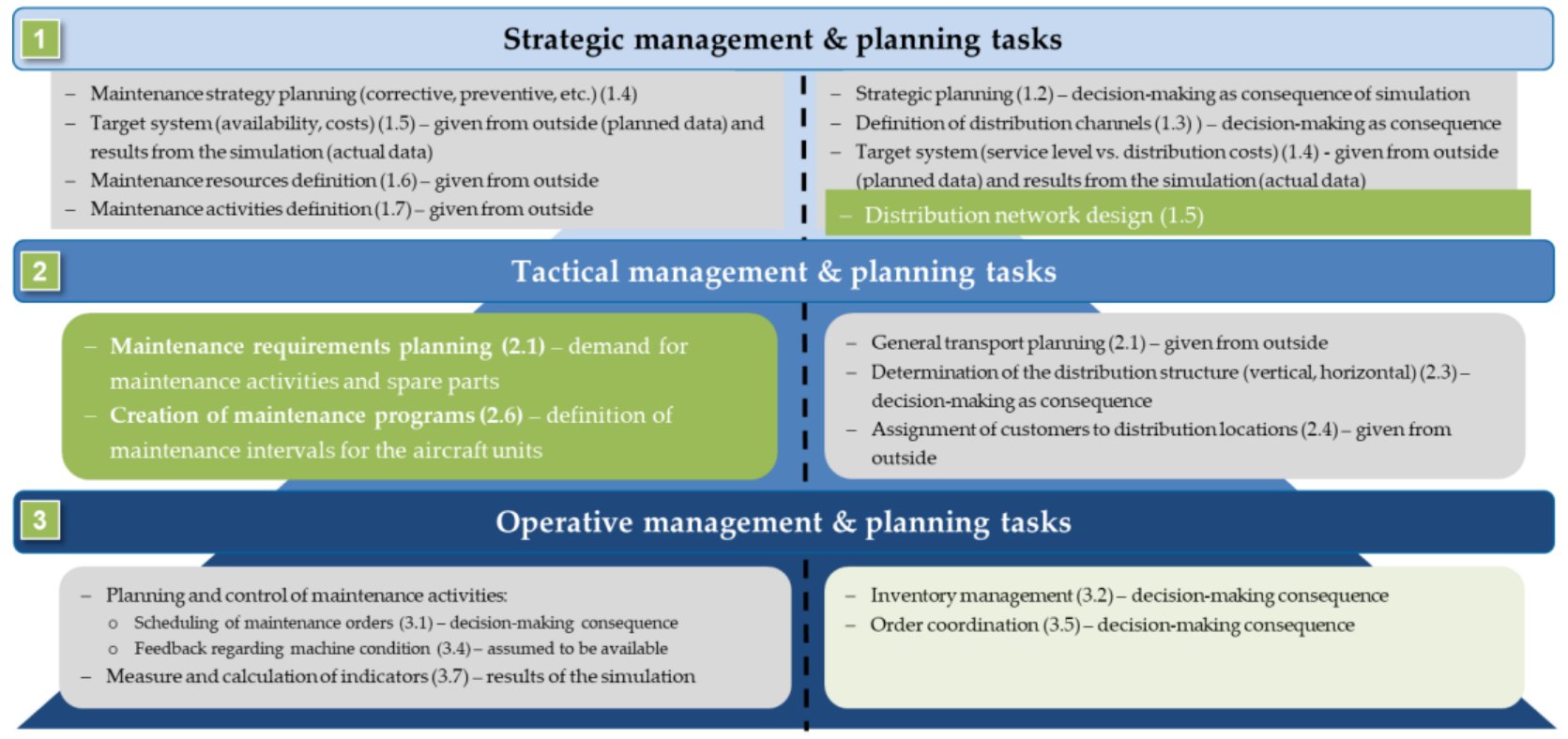

Figure 2. Conceptual model configuration options (in green boxes) based on the management and planning tasks considered (own elaboration).

The management and planning tasks are classified according to time horizons andonly the tasks shown in Figure 2 are considered. Some tasks are inputs for the conceptual model such as the maintenance resources, the target system, and the assignment of maintenance 
locations to distribution centers. Other tasks are the configuration options of the conceptual model. These tasks are those in green boxes in Figure 2. Based on these tasks, the scenarios and models are built. The results are obtained based on the input data and the scenarios and models. Finally, based on the results, the distribution network, channels, distribution strategic planning, inventory management, distribution order coordination, and scheduling of maintenance orders can be decided.

By focusing on the configuration options of the conceptual model, the methodology for its implementation can be determined and the steps to be followed in order to obtain the results are shown in Figure 3:

\section{Step 3: Simulation of:}

- of different distribution network configurations, demand scenarios, maintenance models (planned or unplanned), inventory models, and a comparison of existing brownfield networks vs. potential greenfield networks

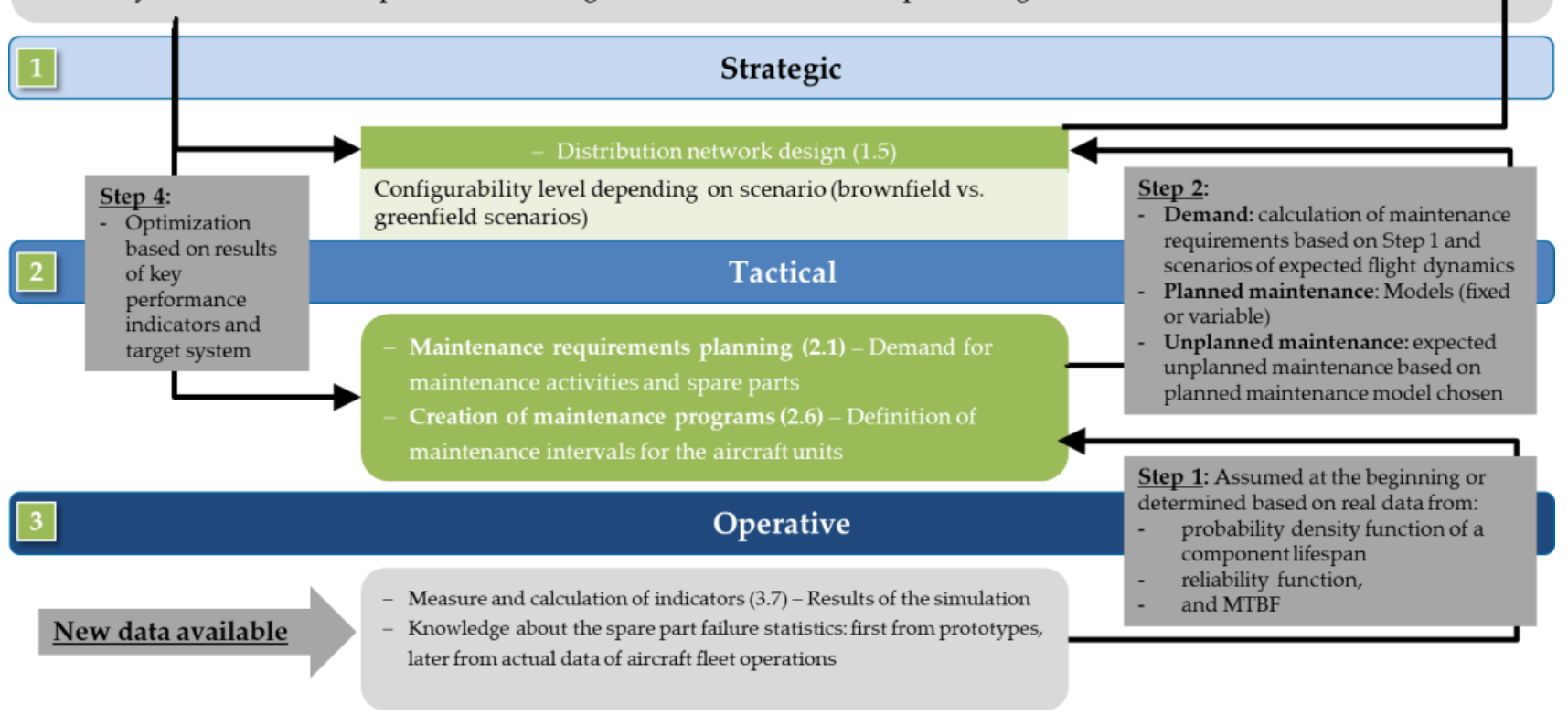

Figure 3. Methodology and steps for applying the maintenance and spare parts distribution model (own elaboration).

\section{Simulation Model Results}

The aim of the simulation model developed was to identify key factors contributing to the optimization of an aircraft fleet's availability throughput its life cycle. The simulation facilitates a comparison among types of distribution networks and planned maintenance intervals to decide which of them is optimal for a company's strategy regarding a certain spare part unit.

\subsection{System Dynamics Model Definition}

\subsubsection{Casual Loop Diagrams}

To identify and evaluate the relationships among factors influencing the conceptual model and the system dynamics model, casual loop diagrams (CLDs) were generated. Two of them are shown as examples for the distribution network and distribution shipments in Figures 4 and 5 . 


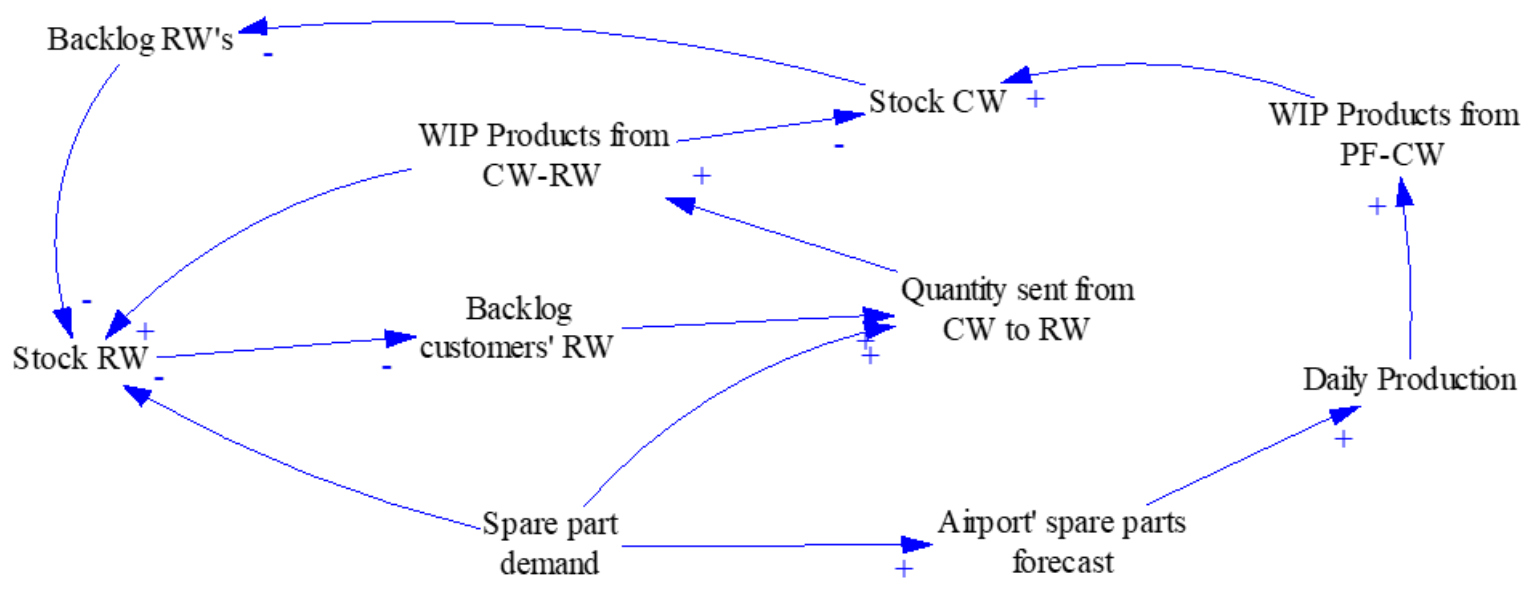

Figure 4. Casual loop diagram (CLD) for operational distribution (own elaboration).

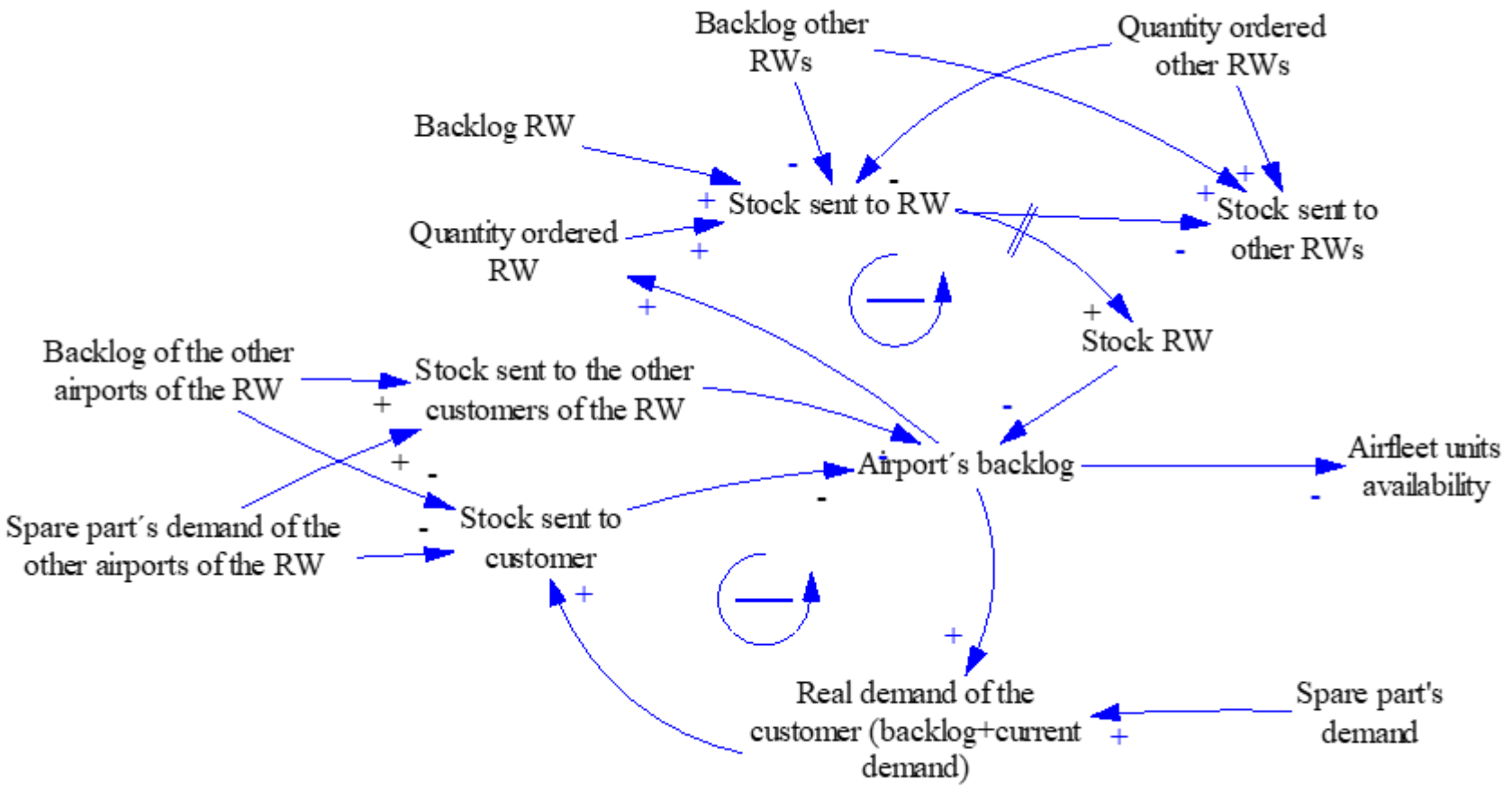

Figure 5. CLD for shipments coordination (own elaboration).

Other CLDs were developed for other factors and sub-models of the conceptual model in order to analyze the relationships among factors to prepare the system dynamics simulation models.

\subsubsection{System Dynamics Sub-Models}

The system dynamics model consists of five sub-models (Figure 6). First, the aircraft fleet sub-model considers the production of the aircraft units and the economic parameters. Second, the forecasting sub-model determines the maintenance requirements. Next, the maintenance program sub-model determines the intervals for planned maintenance activities and the MTBF that initiates unplanned maintenance activities. The fourth sub-model consists of the distribution network including the production facility for spare parts, the warehouses, and their inventory levels, the transport of units between locations, and the delivery of spare parts to the locations where the maintenance activities are performed. Finally, the KPIs sub-model calculates the indicators to evaluate the results: 


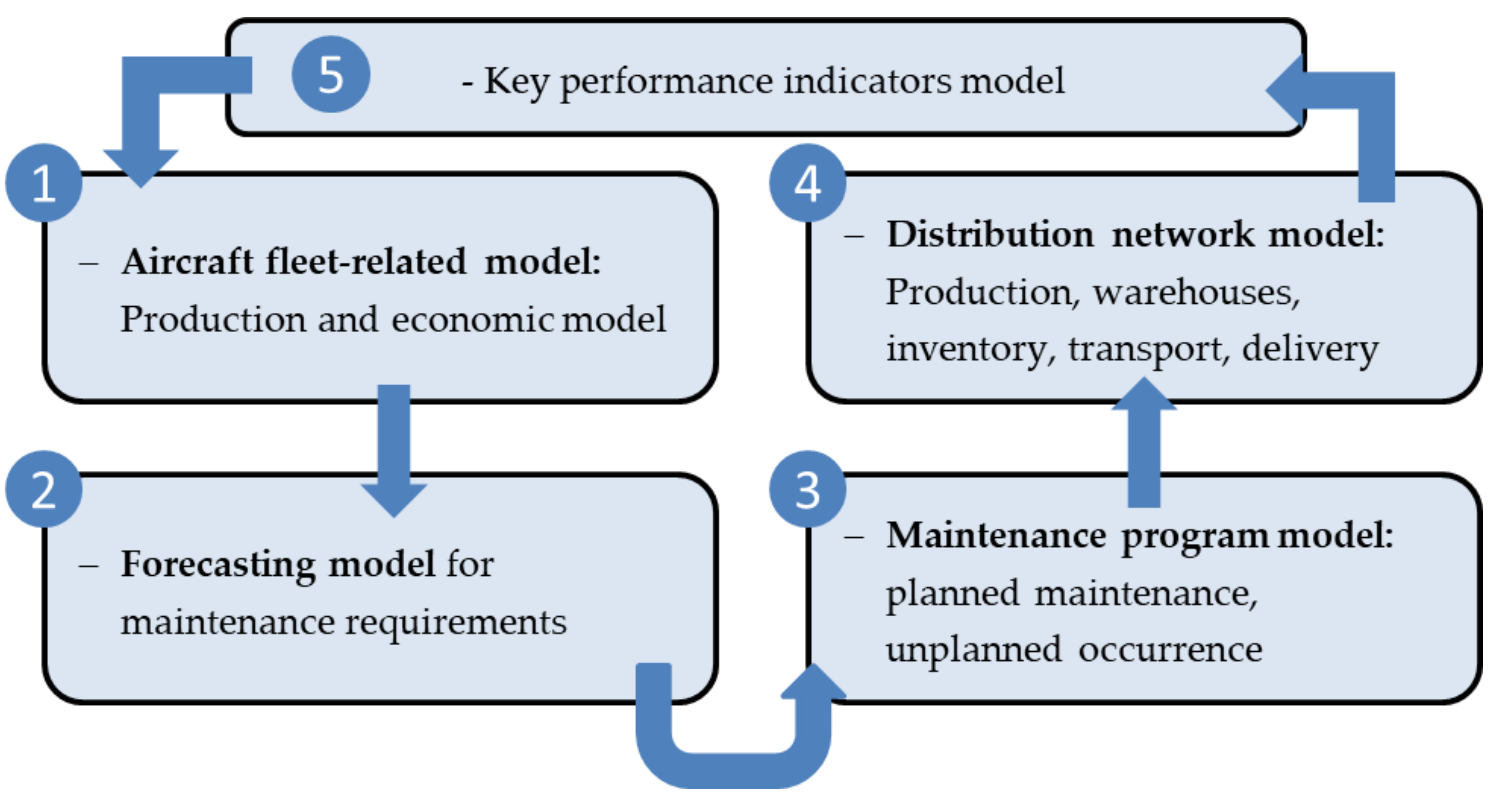

Figure 6. System dynamics model and its five sub-models (own elaboration).

\subsubsection{Aircraft Fleet Sub-Model}

The aircraft fleet sub-model considers the whole life cycle, from production to retirement, for an aircraft unit. Maintenance objects are understood to be those components of technical systems in which maintenance services are performed. Depending on the level of abstraction, this can be a complex technical system or the components of the system, i.e., individual machines, components, parts, technical objects, smaller units, etc. [5]. In the model, an aircraft unit is considered as the technical system. Moreover, the distribution network considers one spare part as an individual component. Therefore, the implications of the distribution network for one spare part in the aircraft fleet units were determined. The maintenance object is the airplane. For this airplane, several units are produced over the simulation period (Figure 7):

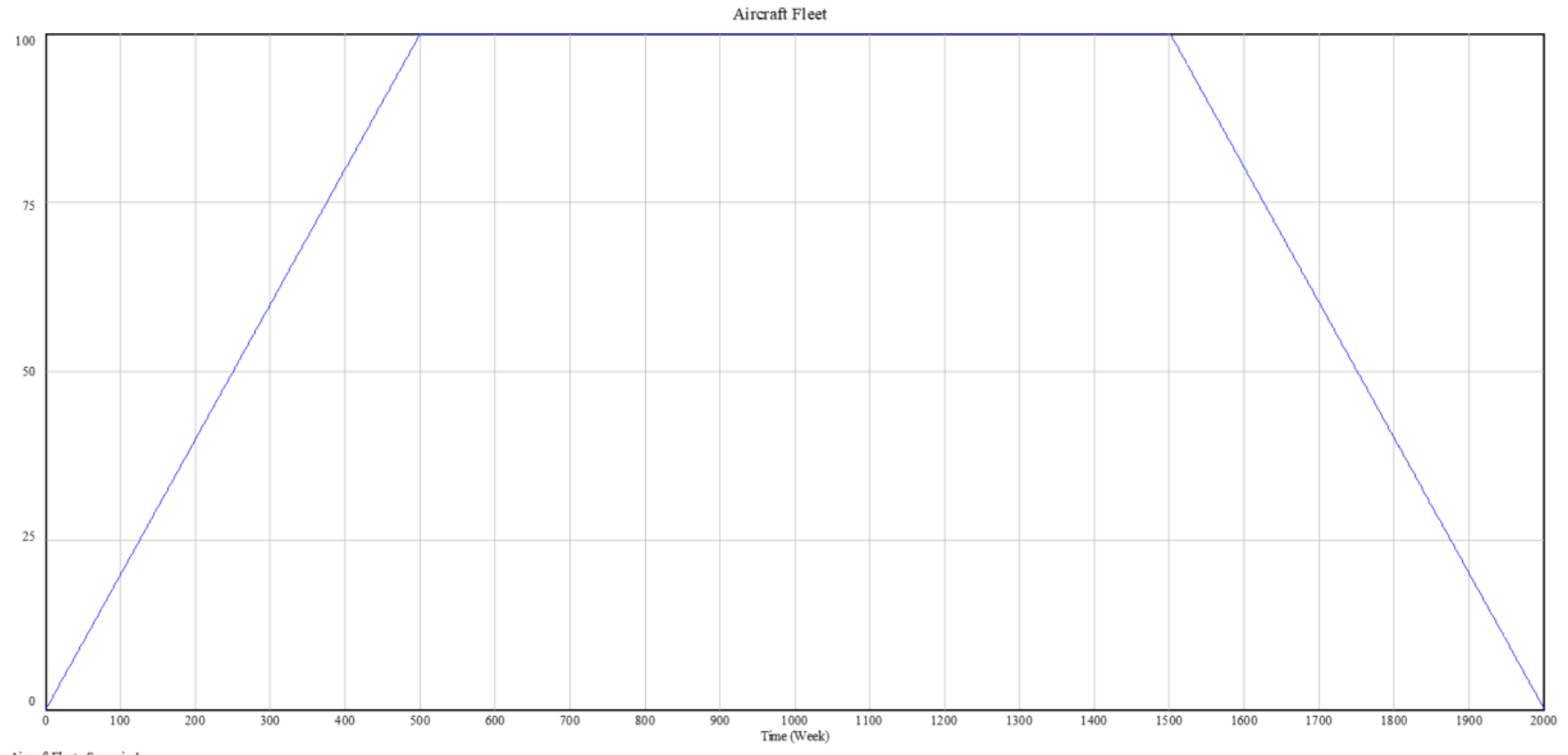

Figure 7. Aircraft fleet over the simulation timeframe (own elaboration). 
Figure 7 shows the first ten years of the simulation, the number of airplanes in the aircraft fleet was increasing until 100 units. Then the aircraft fleet and its number of airplanes were constant until the year thirty or 1500 weeks, then old airplanes are gradually removed from service.

\subsubsection{Forecasting Sub-Model for Maintenance Requirements}

This sub-model forecasts the traffic volume of flights and the expected operating hours for the aircraft fleet. The forecast is built based on the analysis of historical data and by applying moving average or linear regression forecasting methods. Based on this forecast and on the spare parts characteristics of the airplane, the number of components of the spare part per airplane, and the spare part failure probability, the maintenance requirements are determined for each maintenance location of the system dynamics model.

\subsubsection{Distribution Network Sub-Model}

To exemplify the goal of the model, the distribution network in Figure 8 was selected based on a literature review [32]. The production facility follows a make-to-stock strategy in order to satisfy production and maintenance orders from stock. Therefore, production relies on demand forecasts instead of real orders, that is, it followed the "push" principle. Therefore, inaccurate forecasts could lead to an excessive inventory or stock-outs. The distribution network consists of a two stages distribution for a single spare part. Every existing warehouse in a different level determines one new stage. The production facility $(\mathrm{PF})$ has no warehouse and pushes the products to the central warehouse $(\mathrm{CW})$. We hypothesize that the first distribution stage is the central warehouse that should take care of the deliveries for a certain spare parts distribution area. Moreover, every warehouse of the second stage (i.e., regional warehouse) is located in a different region of the distribution area. The central warehouse receives all components produced by the production facility and stores them, except for those spare part units that are sent to the final assembly line when producing the initial aircraft units. These products are standard and finished products at this stage, which means that there is no change in the products and that the only activities performed during distribution are those related with storage and transport. The regional warehouse (RW) or distributor is the second stage. In this warehouse the goods are stored and then delivered to the airports at the appropriate time, which is when the maintenance orders are placed. It is assumed that all maintenance activities, planned and unplanned, are performed at the airport locations available for maintenance purposes.

The distribution network can have different strategies depending on its maintenance order decoupling point or postponement point. A push-strategy means that all spare parts are distributed and sent to the maintenance locations, i.e., the airports. A pull strategy entails the spare partsonly being sent if a maintenance order is placed. A hybrid push-pull strategy implies a push strategy until the maintenance order decoupling point is reached, with a pull strategy after that point. 


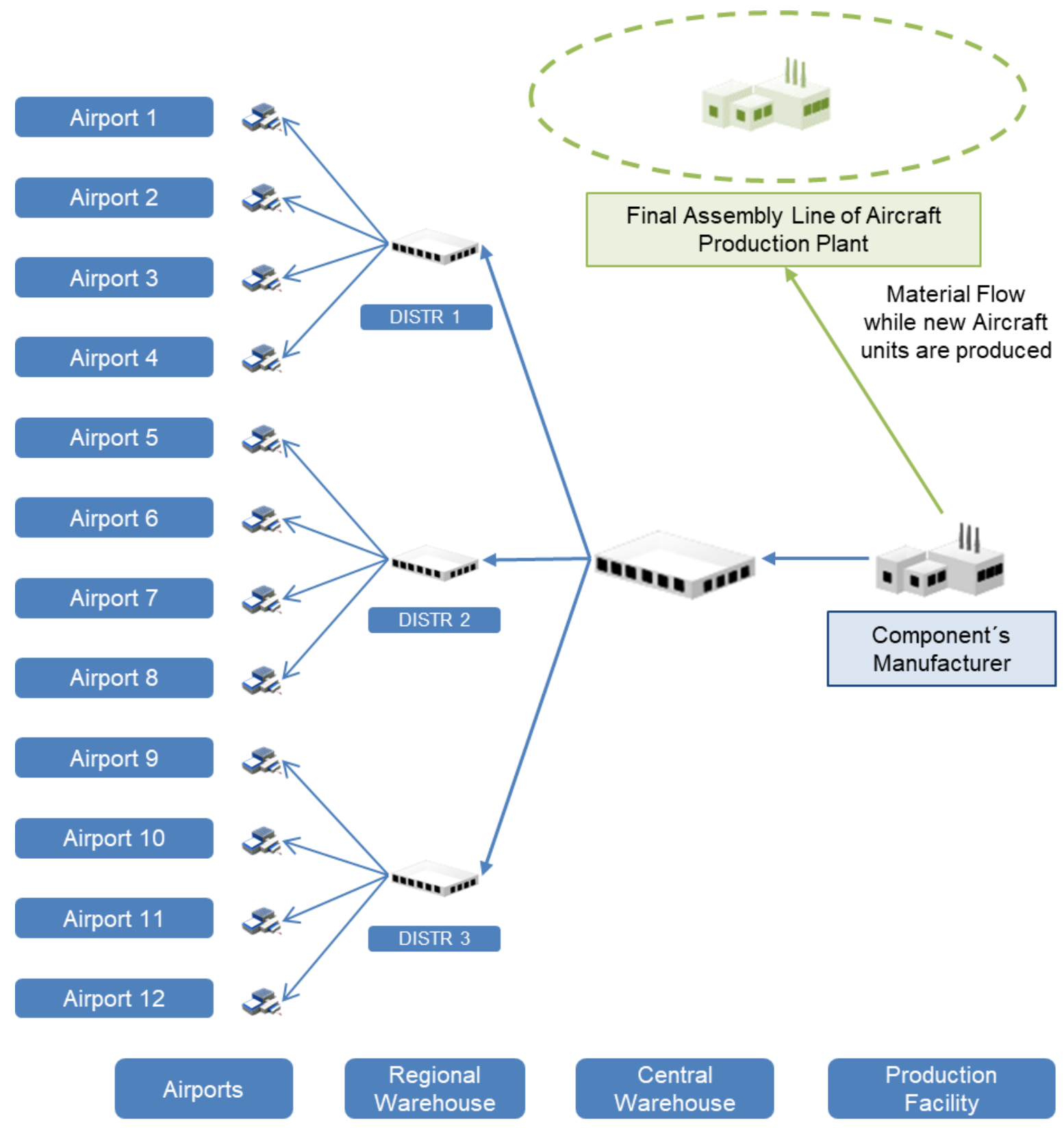

Figure 8. Distribution network sub-model (own elaboration).

\subsubsection{Maintenance Program Sub-Model}

Reactive maintenance and preventive maintenance are considered in the maintenance program sub-model, which considers one spare part for which the intervals for planned maintenance activities are determined. The intervals can be fixed or variable. Based on this, the maintenance activities are performed and the unplanned maintenance activities are derived from them.

For each component, depending on its ABC classification or the criticality analysis, the maintenance programs can be influenced to reach the target levels for each individual component or spare part.

\subsection{Simulation Design}

4.2.1. Time Restrictions and Assumptions

First, the modeler defined a time horizon and time units based on how far into the future the simulation should run. For this study, the simulation was planned to run for 
forty years to evaluate the maintenance and distribution network performance for an airplane lifecycle. It is assumed that a year has fifty weeks of operation. As a result, the time boundaries for the model were as follows:

- Initial time: 0 weeks;

- Final time: 2000 weeks;

- Time step: 1 week;

- Units for time: weeks.

The following assumptions were made related to the points to be fulfilled in order to conduct a comparison between the simulation models for a defined simulation demand scenario:

- The same demand using replication;

- The same replenishment methods used with the same parameters and the same definition of them;

- Same aircraft fleet production rate and total number of aircraft units;

- Same flight traffic volume and operating hours;

- Same failure probability for the spare part component;

- Same initial situation, that is, no backlog to begin with and the same conditions of WIP (products on their ongoing transportation to the customers), the same initial stock in the different warehouses, and initial stock ready to deliver to customers;

- Same number of employees with same initial distribution and same capacity to perform warehouse activities;

- Same supply chain distribution network (production facility, warehouses, etc.);

- Same production logic for all simulation models;

- Same material delays: 1 week of production process, 2 week of transportation lead time between PF and CW, 4 weeks of transportation lead time between $\mathrm{CW}$ and RWs, and 2 weeks of transportation between RWs and airport-maintenance locations;

- Minimum quantity to deliver from central to regional warehouses (trucks'minimum load is 50 units of spare parts). If this quantity is not reached, then the delivery does not take place;

- All models have the same forecasting method and the same changes between them;

- Same inventory management models, reorder-point for pull strategy, and the same coordination of the distribution of spare parts for the push strategy;

- Constant interest rates;

- The backlog of spare part units is treated with the same logic in all models. Airports and distributors with higher backlog levels are prioritized when organizing the delivery of the spare parts;

- Same production limitations: Minimum of 100 products/week, maximum of 300 products/week;

- The warehouses have no stock capacity limitations. It was assumed that outsourcing warehouses for stocks can be found in the nearby with extra-holding costs;

- There were no transport limitation between the different production stages. It was assumed that additional third-party logistics could be found;

- No experts in the field have directly supported the model construction to assign values or to assist the validation of the models.

\subsubsection{Key Performance Indicators}

The KPIs were a selection of parameters from the target system, as defined in Section 3.

\subsubsection{Simulation Models}

Four simulation models were considered in the research study. They resulted from the combination of push or pull strategies and fixed or variable maintenance intervals, as shown in Figure 9: 


\section{Simulation models}

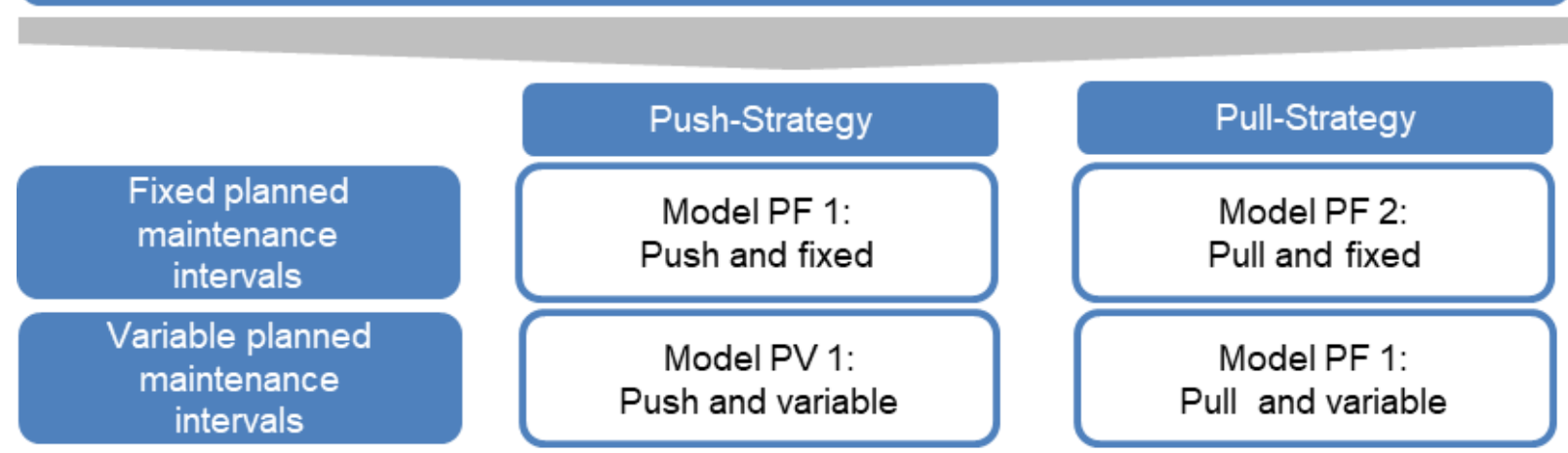

Figure 9. Simulation models developed for the research study (own elaboration).

\subsubsection{Scenarios}

Two different scenarios were generated depending on the spare parts demand level:

- Scenario 1: High demand of spare parts;

- Scenario 2: Low demand of spare parts.

\subsubsection{Model Validation}

A validation of the model was performed using extreme value tests to prove logical responses of the model for maximum and minimum values for the factors. The extreme value test is a method that proves that the model response is plausible when taking extreme values for different input parameters [33]. Some basic physical laws should be observed, for example, when there are no employees the model should not able to meet the spare parts demand. For all the models, we chose the same variables as input and output in order to analyze and validate models. These input variables were the total number of employees, initial stock in the central warehouse, and initial stock in the regional warehouses. From the variation of these variables, the following results can be expected according to the logic of a distribution network:

- For a lower number of employees, then OTD must be lower and total stock should be higher because the production facility provides more products than the employees are able to process. This is shown in Figure 10, where the blue lines refer to the results over the simulation time for 160 employees, while the red lines are for the results for 140 employees and the green lines for 120 employees. It can be seen that when there are fewer employees, then the OTD decreases while the cumulated spare parts backlog, WIP, and stock in network caused by missing manpower increase. This happens because employees perform the warehouse activities and if there are not enough employees then the spare parts are not ready for delivery on time.

- If the initial stock in the central warehouse is lower, the OTD should be lower and stocks should be lower. As expected, this result was obtained.

- If the initial stock in the regional warehouses is lower, the OTD should be lower and stocks should be lower. As expected, this result was obtained. 

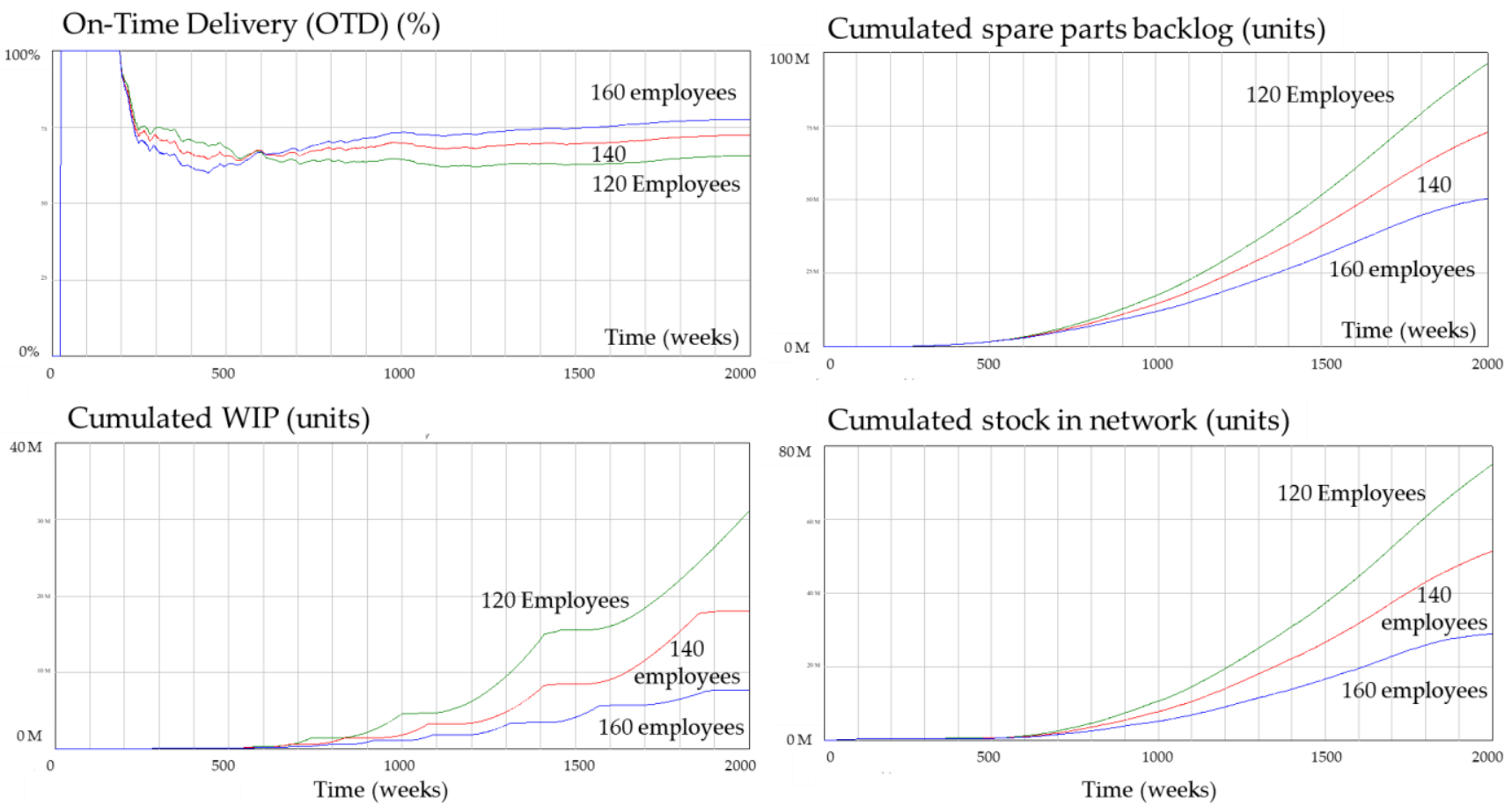

Figure 10. Model validation with the extreme test for the number of employees (own elaboration).

\subsection{Results for the Case Study of an Aircraft Fleet}

Results of the simulation model in the selected scenarios are shown in Tables 2 and 3.

Table 2. Simulation results for the first demand scenario-high demand for spare parts.

\begin{tabular}{|c|c|c|c|c|c|}
\hline No. & Key Indicator & Model PF-1 & Model PF-2 & Model PV-1 & Model PV-2 \\
\hline 1 & $\varnothing$ spare parts demand (units) & 144.4 & 144.4 & 114.8 & 114.8 \\
\hline 2 & On-time delivery (OTD) (\%) & 88.2 & 85.0 & 100.0 & 90.3 \\
\hline 3 & Service level (\%) & 71.0 & 67.4 & 100.0 & 90.1 \\
\hline 4 & $\varnothing$ spare parts backlog (units) & 984 & 998 & 0 & 56 \\
\hline 5 & $\varnothing$ stock in network (units) & 3080 & 3112 & 6586 & 6679 \\
\hline 6 & $\varnothing$ stock in CW (units) & 26 & 1895 & 37 & 5086 \\
\hline 7 & $\varnothing$ stock in RW (units) & 3054 & 1217 & 6549 & 1593 \\
\hline 8 & $\varnothing$ production (units) & 154 & 154 & 129 & 129 \\
\hline 9 & Ø WIP (Work-In-Progress) (units) & 3650 & 1795 & 7046 & 2053 \\
\hline 10 & $\varnothing$ aircraft availability (\%) & 60.0 & 59.8 & 83.7 & 82.6 \\
\hline 11 & $\varnothing$ aircraft on ground $(\%)$ & 40.0 & 40.2 & 16.3 & 17.4 \\
\hline 12 & $\begin{array}{l}\varnothing \text { interval for planned } \\
\text { maintenance (operating hours) }\end{array}$ & 706 & 706 & 1567 & 1567 \\
\hline 13 & $\begin{array}{l}\varnothing \text { interval for unplanned } \\
\text { maintenance (operating hours) }\end{array}$ & 1974 & 1974 & 1577 & 1577 \\
\hline
\end{tabular}


Table 3. Simulation results for the second demand scenario-low demand for spare parts.

\begin{tabular}{|c|c|c|c|c|c|}
\hline No. & Key Indicator & Model PF-1 & Model PF-2 & Model PV-1 & Model PV-2 \\
\hline 1 & $\varnothing$ spare parts demand (units) & 28.6 & 28.6 & 22.0 & 22.0 \\
\hline 2 & On-time delivery (OTD) (\%) & 100 & 87.8 & 100 & 85.9 \\
\hline 3 & Service level (\%) & 100 & 88.3 & 100 & 86.9 \\
\hline 4 & $\varnothing$ spare parts backlog (units) & 0 & 27.1 & 0 & 29.4 \\
\hline 5 & $\varnothing$ stock in network (units) & 3111 & 3145 & 5530 & 5576 \\
\hline 6 & $\varnothing$ stock in CW (units) & 64 & 1731 & 67 & 3994 \\
\hline 7 & $\varnothing$ stock in RW (units) & 3047 & 1414 & 5463 & 1581 \\
\hline 8 & $\varnothing$ production (units) & 31 & 31 & 27 & 27 \\
\hline 9 & $\varnothing$ WIP (Work-In-Progress) (units) & 3168 & 1528 & 5567 & 1669 \\
\hline 10 & $\varnothing$ aircraft availability (\%) & 79.7 & 77.0 & 83.7 & 80.8 \\
\hline 11 & $\varnothing$ aircraft on ground (\%) & 20.3 & 23.0 & 16.3 & 19.2 \\
\hline 12 & $\begin{array}{l}\varnothing \text { interval for planned } \\
\text { maintenance (operating hours) }\end{array}$ & 706 & 706 & 1567 & 1567 \\
\hline 13 & $\begin{array}{l}\varnothing \text { interval for unplanned } \\
\text { maintenance (operating hours) }\end{array}$ & 1974 & 1974 & 1577 & 1577 \\
\hline
\end{tabular}

As can be observed from Table 2, the best results in terms of aircraft availability were for the PV-1 model, the push strategy with variable planned maintenance intervals. However, this model presents 5000 units more in WIP than the PV-2 model, which has only $1.1 \%$ lower aircraft availability. Moreover, the PV-1 model has units stored mainly in the regional warehouses while the PV-2 model has approximately $75 \%$ of units in the central warehouse. To decide which of the configurations is is optimal in terms of cost and spare part type, other analyses must be realized. Another important aspect is the fact that the variable models, PV- 1 and PV-2, had almost $25 \%$ lower consumptions of spare parts due to the dynamic changes of maintenance intervals.

As can be observed from Table 3, the best results in terms of aircraft availability were for the PV-1 model, the push strategy with variable planned maintenance intervals. However, this model presents almost 4000 units more in WIP than the PV-2 model, which hasonly $2.9 \%$ lower aircraft availability. In addition, it can be observed how the models with variable planned maintenance intervals, PV-1 and PV-2, present better aircraft availability. Furthermore, the models with a pull distribution strategy, PF-2 and PV-2, present lower WIP units, service level, and OTD compared to the push strategy models. This is a result of the allocation of stock closer to maintenance locations in the push strategy models, PF-1 and PV-1, as the units are stored mainly in the regional warehouses. As for the first scenario, in order to be able to decide which of the configurations is the best one in terms of cost and spare part type, other analyses must be realized. Another important aspect is the fact that the variable models, PV- 1 and PV-2, had almost $25 \%$ lower consumptions and approximately $13 \%$ lower production of spare parts due to the dynamic changes of maintenance intervals.

\subsection{Managerial Implications}

Based on the conceptual model and the simulation study performed, the steps presented in Figure 11 can be derived as a methodology to be used by managers when deciding how to design, manage, improve, and implement distribution networks for spare parts management: 


\begin{tabular}{|c|c|c|}
\hline & 1 & $\begin{array}{l}\text { Scenarios: Passenger demand between locations } \\
\text { Scenarios: Flights per aircraft type }\end{array}$ \\
\hline & & 2 Expected (demand) scenario \\
\hline $\begin{array}{l}\text { Expected average aircraft units of the fleet } \\
\text { Age and condition of aircraft units }\end{array}$ & 3 & Operating hours per aircraft type (anual) \\
\hline $\begin{array}{l}\text { Historical data: Probability density function of } \\
\text { component lifespan, reliability function, MTBF }\end{array}$ & 4 & Spare part unit demand (anual) \\
\hline $\begin{array}{l}\text { Fix or variable periods-data input for } \\
\text { formula if needed, legal, security, } \\
\text { environmental and other requirements }\end{array}$ & 5 & Planned maintenance intervals determination \\
\hline $\begin{array}{l}\text { Fix or variable periods - data input for } \\
\text { formula if needed }\end{array}$ & 6 & $\begin{array}{l}\text { Expected requirements of spare parts } \\
\text { (quantity, location and timing) }\end{array}$ \\
\hline $\begin{array}{l}\text { Alternative distribution network } \\
\text { Organizational division } \\
\text { Brownfield or greenfield }\end{array}$ & 7 & Selection of a distribution network structure \\
\hline Inventory management methods & 8 & Selection of an inventory management model \\
\hline
\end{tabular}

11. Comparison of alternative models Optimization of existing model

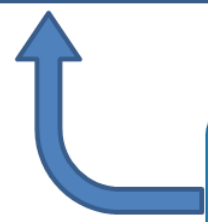

Simulation

Results of:

- Aircraft availability, delays, and cancellations

- Need and allocation of related resources (tools, transport, warehouse, production, staff capacity)

Figure 11. Managerial implications—-methodology and steps (own elaboration).

Based on the methodology applied for all spare parts components, thedecisions outlined in Figure 12 can be analyzed.

\section{Multiple or single distribution network}

Distribution network for spare parts of multiple aircraft fleets

Distribution network depending on maintenance activities (specialization, planned/unplanned)

\section{Distribution network for spare parts groups (type of products)}

Level of maintenance posible at airport locations

Figure 12. Decision-making influenced by the methodology of the research study (own elaboration).

\section{Conclusions}

This research provided a methodology and results from a case study analysis to assess the design of distribution networks for spare parts throughput and the related whole life cycle cost of an airplane. This sort of evaluation is normally needed when making decisions regarding new distribution network configurations, distribution strategies, and maintenance program definitions. For this reason, many different agents can obtain benefits and methodological inputs for their assessments such as suppliers, manufacturers, airlines, users, and maintenance companies.

The methods described in this document can be applied throughout the life cycle of an aviation item to examine trade-offs between distribution performance, inventory cost 
and aircraft availability. In this context, after the realization of this research study, the importance of distribution network design and management for spare parts in the aviation industry has been demonstrated. We draw the following conclusions from this study:

- System dynamics provides the necessary notation and functionality to design distribution related models using Vensim (commercial software);

- Simulation of frameworks can be used to compare different distribution network approaches as well as different maintenance planning models;

- According to the results of the comparison here, it has been shown that in most cases a push strategy together with variable maintenance intervals gives a better response for aircraft availability, while a pull strategy with variable maintenance intervals provides better results in terms of inventory costs. Moreover, the variable maintenance intervals are a key factor to reduce the consumption of spare parts and the related maintenance time for replacements. The better response of the push strategy in terms of aircraft availability is due to the stable and homogenous demand among airports. The demands analyzed did not have high volatility or constant demand pattern changes. As a result, the allocation of stocks close to the maintenance locations provided better results. In terms of cost, further analysis must be performed to determine which configuration is optimal. This also depends on a company's goal and the overall system condition.

- The proposed approach can increase the efficiency of distribution networks. It shows how the proposed conceptual model and its methodology can provide a useful tool for managers to compare different distribution network designs and maintenance programs and decide which best meets the target aircraft availability with the lowest costs possible, increasing delivery service with less stocks and more efficient manpower allocation. The methods and strategies used have their unique advantages and disadvantages and each company's objectives and external environment will determine the preference of use.

Two major limitations of the research paper were: no experts in the field were involved in the development process of the conceptual or the simulation models and the models were not applied to any real aircraft fleet for maintenance and distribution management.

In summary, it is important to determine other means of investigation or possible ways to improve the performed project. Future research might consider the following activities:

- Extension of the conceptual model for other distribution and maintenance planning and management tasks;

- Detailed analysis of the factors of the simulation model;

- Extension of the functionality of the simulation model including promotions, price fluctuations, economic context, cost of activities, number of spare parts, improvement of demand forecasts methods, increased flexibility of the distribution network by allowing different routes, different aggregation of customers as well as different distances between stages and the consideration of the product cycle;

- Application of the conceptual model methodology and the simulation model to a real-case distribution network for spare parts management.

Author Contributions: Conceptualization, M.G.-G. and S.G.-G.; data curation, S.G.-G. and J.G.-G.; formal analysis, S.G.-G.; Investigation, S.G.-G.; methodology, S.G.-G.; resources, S.G.-G.; software, S.G.-G.; supervision, M.G.-G. and S.G.-G.; validation, S.G.-G.; writing-original draft, S.G.-G. and J.G.-G. All authors have read and agreed to the published version of the manuscript.

Funding: This research received no external funding.

Conflicts of Interest: The authors declare no conflict of interest. 


\section{References}

1. Pawellek, I.G. Planung der Instandhaltung. In Tegrierte Instandhaltung und Ersatzteillogistik; Springer: Berlin/Heidelberg, Germany, 2013.

2. Instandhaltung Technischer Systeme: Methoden und Werkzeuge zur Gewährleistung eines Sicheren und Wirtschaftlichen Anlagenbetriebs; Schenk, M. (Ed.) Springer: Heidelberg, Germany, 2009.

3. Handbook of Maintenance Management and Engineering; Ben-Daya, M.; Duffuaa, S.O.; Raouf, A.; Knezevic, J.; Ait-Kadi, D. (Eds.) Springer: London, UK, 2009; Volume 7.

4. Matyas, K. Instandhaltungslogistik: Qualität und Produktivität Steigern, 5th ed.; Carl Hanser Verlag, Ed.; Wien: München, Germany, 2013.

5. Mcadam, R.; Duffner, A. Implementation of total productive maintenance in support of an established total quality programme. Total Qual. Manag. 1996, 7, 613-630. [CrossRef]

6. Chelson, J.V.; Payne, A.C. Reavill., LRC. Management for Engineers, Scientists and Technologists, 2nd ed.; Wiley: Chichester, UK, 2005.

7. Kuhn, A.; Schuh, G.; Stahl, B.N. Nachhaltige Instandhaltung: Trends, Potenziale und Handlungsfelder Nachhaltiger Instandhaltung; Ergebnisbericht der vom BMBF geförderten untersuchung nachhaltige instandhaltung; VDMA-Verlag: Frankfurt am Main, Germany, 2006.

8. Garrido, S.G. Organización y Gestión Integral de Mantenimiento; Ediciones Diaz de Santos: Madrid, Spain, 2010.

9. Sherbrooke, C.C. METRIC: A multi-echelon technique for recoverable item control. Oper. Res. 1968, 16, 122-141. [CrossRef]

10. Agrawal, S.; Singh, R.K.; Murtaza, Q.A. literature review and perspectives in reverse logistics. Resour. Conserv. Recycl. 2015, 97, 76-92. [CrossRef]

11. Garg, A.; Deshmukh, S.G. Maintenance management: Literature review and directions. J. Qual. Maint. Eng. 2006, 12, 1355-2511. [CrossRef]

12. Alrabghi, A.; Tiwari, A. State of the art in simulation-based optimisation for maintenance systems. Comput. Ind. Eng. 2015, 82, 167-182. [CrossRef]

13. Bacchetti, A.; Saccani, N. Spare parts classification and demand forecasting for stock control: Investigating the gap between research and practice. Omega 2012, 40, 722-737. [CrossRef]

14. Gebauer, H.; Kucza, G.; Wang, C. Spare parts logistics for the Chinese market. Benchmarking Int. J. 2011, 18, 748-768. [CrossRef]

15. Ford, A. Modeling the Environment: An Introduction to System Dynamics Modeling of Environmental Systems; Island Press: Washington, DC, USA, 1999.

16. Forrester, J.W. Counterintuitive Behavior of Social Systems; Chap. 1 on toward Global, Equilibrium; Meadows, D., Meadows, D., Eds.; Pegasus Communications: Walthan, MA, USA, 1973.

17. Márquez, A.C. Dynamic Modelling for Supply Chain Management: Dealing with Front-End, Back-End and Integration Issues; Springer Science \& Business Media: London, UK, 2010.

18. Angerhofer, B.J.; Angelides, M.C. System dynamics modelling in supply chain management: Research review. In Proceedings of the 2000 Winter Simulation Conference Proceedings, Orlando, FL, USA, 10-13 December 2000; Volume 1, pp. 342-351.

19. Sterman, J.D. Business Dynamics: Systems Thinking and Modeling for a Complex World; Irwin/McGraw-Hill: New York, NY, USA, 2000.

20. Forrester, J.W. Industrial Dynamics, 4. Auflage; MIT Press: Cambridge, UK, 1969.

21. Schröter, M. Strategisches Ersatzteilmanagement in Closed-Loop Supply Chains; Deutscher Universitäts-Verlag: Wiesbaden, Germany, 2006.

22. Campuzano, F.; Mula, J. Supply Chain Simulation: A System Dynamics Approach for Improving Performance; Springer Science \& Business Media: Berlin, Germany, 2011.

23. Forrester, J.W. Grundzüge einer Systemtheorie, Deutsche Übersetzung; Zahn: Wiesbaden, Germany, 1972.

24. Dhillon, B.S. Engineering Maintenance: A Modern Approach; CRC Press, Taylor \& Francis Group: Boca Raton, FL, USA, 2002.

25. Wannenwetsch, H. Integrierte Materialwirtschaft, Logistik und Beschaffung; Springer: Berlin/Heidelberg, Germany, 2014.

26. Pfohl, H. Logistiksysteme, Betriebswirtschaftliche Grundlagen, 8th ed.; Springer: Berlin/Heidelberg, Germany, 2010.

27. Chopra, S.; Meindl, P. Supply chain management. strategy, planning \& operation. In Das Summa Summarum des Management; Springer: Berlin/Heidelberg, Germany, 2007.

28. Schuh, G.; Stich, V.; Wienholdt, H. Logistikmanagement; Springer: Berlin/Heidelberg, Germany, 2013.

29. Sebastian, H.J. Optimierung von Distributionsnetzwerken. In BoD-Books on Demand; EAGLE: Leipzig, Germany, 2013.

30. Siller, U. Optimierung Globaler Distributionsnetzwerke: Grundlagen, Methodik, Praktische Anwendung; Gabler Verlag: Wiesbaden, Germany, 2011.

31. Wildemann, H. Entwicklungspfade der logistik. In Das Beste Der Logistik; Springer: Berlin/Heidelberg, Germany, 2008.

32. Schulte, C. Logistik: Wege zur Optimierung der Supply Chain; Vahlen: Munich, Germany, 2008.

33. Wensing, T. Periodic Review Inventory Systems; Springer: Berlin, Germany, 2011; Volume 651. 